\title{
A RACIONALIZAÇÃO DO CONFLITO IMPÉRIO X PAPADO NO FINAL DO SÉCULO XIII
}

Cléa Pitt Goldman*

StNTESE - Transformações na sociedade medieval levaram no século XIII ao fortalecimento do poder temporal. A comunidade cristã, única dirigida pelo papa, era questionada. O conflito que resultou de duas forças - de um lado o poder real e de outro o poder papal - deixou claro que o poder temporal procurava se fortalecer e tornar-se independente do poder papal. Felipe, O Belo de França, que lançava o desafio, teve ao seu lado os legistas que fundamentavam sua argumentação, entre outros textos, no Direito Romano. Entre os pensadores da época ao lado do papado destacase o estudo em profundidade produzido por Egídio Romano, De Ecclesiastica Potestate.
ABSTRACT - During the XIII century the struggle of the two powers of the Cristian world becomes critical with the fight between Philip, the Fair, and Boniface VIII. Giving support to Philip, the Fair, there are the works of the legists, and defending the Pope we have the theologian Aegidius Romanus.

O século XIII foi um período de efervescência de idéias, convidando à investigação e à discussão.

Assim, a necessidade de encontrar fundamentos na razão afetou o próprio pensamento religioso, provocando mudança no conceito tradicional de teologia com a aproximação do pensamento filosófico aristotélico.

Podemos inserir neste contexto a disputa entre o poder real e o papal; conflito entre o rei Felipe, O Belo, de França e o papa Bonifácio VIII.

Por outro lado, o Direito Romano provocava um interesse cada vez maior. 0 contato com esse patrimônio cultural do mundo clássico ocorreu a partir da obra da Escola de Tradutores, cuja existência, testificada desde meados do século XII, alcançou sua plenitude um século depois, permitirá entrar em contato, através de uma complexa série de versões, com a filosofia e a cosmologia clássica, em especial a de Aristóteles. De forma simultânea à recepção da filosofia, se produziu o estudo do Direito Romano.

* Universidade Estadual Paulista - USP.

\begin{tabular}{|l|c|c|c|c|c|}
\hline VERITAS & Por to Alegre & v. 40 & $\mathrm{n}^{\mathrm{9}} 159$ & Setembro 1995 & p. 639-642 \\
\hline
\end{tabular}


A difusão do Direito Romano provocou não só uma série de fenômenos de caráter estritamente jurídicos, como decisivas conseqüências no terreno político social.

Assim, aparece um grupo profissional e também social constituído pelos especialistas em Direito saídos da Universidade, homens que não pertencem ao clero e trazem uma mentalidade laica e muitas vezes antieclesiástica. Muitos deles eram professores de universidade, como Bolonha, Toulouse e Montpellier, e atuaram como advogados, chanceleres e conselheiros de monarcas.

Chamamos a atenção que o espírito laico não poderia nascer a não ser no seio de uma sociedade onde a distinção entre clérigos e laicos, entre espiritual e temporal, entre autoridade laica e autoridade eclesiástica é notadamente marcada.

A atitude anticlerical não apareceu somente entre os legistas. Vários escritos do século XIII, como fábulas, farsas, sátiras, atestavam uma grande verve anticlerical que cada vez se tornava menos dissimulada. Foram numerosos manifestos, panfletos, revoltas, que no decorrer deste século, testemunharam a hostilidade crescente de certos elementos laicos contra o clero. ${ }^{1}$

Para administrar seu reino, Felipe IV, da França, serviu-se de personagens consagrados ao estudo do Direito Romano, os legistas. O duplo estudo, o do direito consuetudinário e o direito escrito, permitiu comparar as sociedades, antiga e feudal, considerando que o Direito Romano se opunha quase completamente ao direito consuetudinário, considerando que na sociedade antiga o Estado era forte e a vontade do imperador tinha força de lei, e convencidos da superioridade da sociedade antiga os legistas pretendiam que o rei e seus auxiliares possuíssem todos os poderes que o código romano atribuia ao imperador

Os principais conselheiros de Felipe, o IV da França, foram: Pedro Flotte, Guilherme Nogaret, Enguerrand de Marigny e Pedro Dubois. ${ }^{2}$.

A obra de Pedro Dubois Disputatio inter clericum et militem, escrito antes da obra de Egídio Romano, De Ecclesiatica Potestate, apresentou a mais radical tese em apoio ao poder real.

As discussões que surgiram entre os defensores de ambos os poderes deram origem aos primeiros tratados sistemáticos sobre a Igreja e a supremacia do poder papal. Assim, destacaram-se com suas obras: Henrique de Cremona, De Potentia Papae (1301), Egídio Romano, De Ecclesiastica Potestate (1301-1302), Thiago de Vi-

1 "Nós todos grandes do reino, que refletimos com atenção que o reino foi adquirido, não pelo direito escrito ou pela arrogância dos clérigos, mas pelo soldo dos guerreiros, nós estatuímos e sancionamos pelo presente decreto, sobre juramento de todos, que [...]". Documentos, Liga dos Barões no curso do século XIII se encontram reunidos nos "Layette du Trésor de Chartres", editado por Taulet Lagarde, in La naissance de l'Esprit Laique, p. 192-193.

2

"Muitas iniciativas de Felipe, $O$ Belo e de seus filhos encontram-se sob a responsabilidade de uma política atribuida aos legistas que o cercavam, em particular Pedro Dubois, Pedro Flotte, Guilherme Nogaret. O normando Pierre Dubois, advogado real, reivindicava para Felipe, O Belo, nada menos que a dominação da Europa e a incorporação do domínio pontifical aos seus Estados. Pedro Flotte de Auvergne, chanceler do rei, não acompanhou as vastas concepções revolucionárias de seu colega, mas este pequeno advogado zarolho, como o chamava Bonifácio VII, demonstrou em seu procedimento uma insolência e uma brutalidade vergonhosa. A malícia de um e de outro foi ultrapassada pelo advogado gascão Guilherme de Nogaret, o sacrilego agressor de Bonifácio VIII". F. MORRET J. Histoire de l'Eglise. Tomo I, Paris, 1930. 
terbo, De Regimine Christiano, João de Paris, De potestate Regia et Papali, e outros.

Grande parte da argumentação utilizada por Egídio Romano provém de fontes bastante conhecidas, como Santo Agostinho, Aristóteles, Hugo de São Vítor, São Bernardo de Claraval, a Bíblia, o Direito Canônico.

Egídio Romano, defendendo a supremacia pontifícia, a plenitudo potestatis, esforçou-se para provar que o papa era superior ao rei, não só quanto à autoridade, mas em todos os aspectos da vida temporal: o domínio do papa se estende por todo mundo, enquanto o do rei é restrito; se os reis não se mostram dignos, o papa poderá depô-los.

Considera que o poder papal é ilimitado, não podendo ser avaliado quanto ao peso, número ou medida e que o papa não é somente considerado como sucessor de Pedro, mas vigário de Cristo e vigário de Deus sobre a terra, ou seja, seu legítimo representante.

Afirma ainda que a Igreja pode exercer jurisdição temporal, não importa a origem dos casos: eles devem estar sob o poder da Igreja, porque tal poder é sem peso, número ou medida e acrescenta que o sumo pontífice tem o poder no qual se concentra todo o poder, pois corresponde à plenitude do poder.

Egídio Romano preocupou-se também em demonstrar as direções e os limites do poder papal no que concerne às coisas temporais e como o papa conserva os dois gládios sob a sua autoridade.

O papa é identificado como o homem espiritual que julga todos, todas as coisas, mas ele mesmo não é julgado por ninguém, e que pela regra espiritual era senhor dos reis terrenos. Considerando-se que esta conclusão está implícita em toda ordem do universo, a conseqüência prática desse argumento estava na asserção de que toda legitimidade da autoridade política deriva do sumo pontífice e estava sujeita ao seu controle.

Seu argumento favorito da harmonia do universo o levou a fazer o paralelo e a comparação com o corpo e a alma. Pois toda substância corporal é regida pela espiritual e toda substância espiritual é regida pelo papa.

Afirma que o poder secular pode impor obediência através do juízo de sangue, mas os eclesiásticos exercem esse poder através da censura eclesiástica e pela excomunhão, nunca pelo juízo de sangue.

Utiliza o argumento de sua preferência sobre a plenitude do poder na intrínseca superioridade temporal do papa, afirmando que a posse dos bens materiais está sujeita ao poder espiritual, mas pela própria perfeição deste era necessário deixar que outros cuidassem desses bens para que os sacerdotes exercessem de maneira mais completa as suas funções.

Como parte de sua argumentação afirma que a alma domina o corpo, o poder sacerdotal que domina as almas domina também os corpos e as coisas temporais. Este argumento é utilizado isoladamente ou em correspondência ao da ordem do universo ou completado com a idéia de domínio. Como reforço dessa concepção, Egídio afirma que o dominium sobre as coisas do universo pertence a Deus, portanto os homens afastados de Deus não podem exercer nenhum direito de propriedade. Todos os homens são pecadores e só poderiam conciliar-se com Deus atra- 
vés da Igreja, o que implicava ter a mesma no comando geral sobre todos os bens terrenos. Reclamava para a Igreja a forma de dominium maximum.

Egídio Romano baseia parte de sua argumentação na hierarquia da classificação bastante típica do pensamento medieval, demonstrando por asserção que os elementos temporais mais grosseiros eram governados pelas coisas mais sutis, os mais baixos espirituais pelos mais altos, seguindo-se a aplicação a um grande número de exemplos (hierarquia dos anjos, animais, vegetais, etc). Assim, completa que ninguém duvida que as coisas divinas são mais perfeitas que as humanas, e as celestes, que as terrenas, e as espirituais, que as corporais, se sujeite e esteja ordenado ao poder sacerdotal, e principalmente ao poder do sumo pontífice, que é o poder divino e celeste.

A teoria das duas espadas, isto é, dois gládios, foi citada com freqüência, acompanhada da citação de Lucas XXII, 38, como fundamento da doutrina concernente às relações entre os poderes temporal e espiritual. Esta evolução atingiu seu ponto culminante com o texto da bula Unam Sanctam, onde a referência ao texto de Lucas é colocada não como uma afirmação da doutrina mas como seu fundamento.

Os dois movimentos complementares e opostos que comandaram as lutas pelo poder no final do século XIII caracterizaram-se pela afirmação da supremacia monárquica, representado o poder civil de um lado, e pela defesa da plenitude do poder papal, de outro. 